\title{
Factors Affecting Knowledge Transfer in International Construction Joint Venture Projects
}

\author{
Achara Khamaksorn ${ }^{1}$, Esra Kurul ${ }^{2}$ and Joseph Handibry Mbatu Tah ${ }^{3}$
}

\begin{abstract}
Globalization has particularly strengthened over the last two decades. International Joint Ventures (IJVs) between multinational organisations in developed and developing countries are considered to be a successful strategy in order to benefit from international market opportunities in the globalised world. Knowledge Transfer (KT) is an important process where an organisation identifies and learns from specific knowledge which exists in another organisation or in its different parts. In the construction industry, globalization together with the information revolution and the improved knowledge-based economy has fundamentally altered the market. The main aim of this study is to identify key factors that affect and influence knowledge transfer processes in International Construction Joint Venture (ICJV) Projects. An organisation's effectiveness in learning and transferring knowledge depends on a number of factors that facilitate an organisation's capability to acquire and use knowledge. They include knowledge facilitators and knowledge transfer methods and mechanisms, as well as factors which influence a ICJV's performance. Key enabling and inhibiting factors influencing knowledge transfer in ICJVs will be explored and described. As such, the foundation for a better understanding of how knowledge in ICJV projects is transferred and adopted is built. A conceptual framework based on the key concepts and the key enabling and inhibiting factors that influence knowledge transfer will be developed through future research.
\end{abstract}

Keywords - Knowledge Transfer, International Construction, Joint Venture.

\section{INTRODUCTION}

Globalization has particularly strengthened over the last two decades. There has been an unprecedented change in the nature of global business environment [1]. Joint Ventures (JVs), a special type of strategic alliance which offers a unique opportunity to combine the distinctive competencies and the complementary resource of participating firms. An International Joint Ventures (IJVs) is defined as a joint venture with at least one partner headquartered outside the joint venture's country of operation [2]. IJVs between multinational organisations in developed and developing countries are considered to be a successful strategy in order to benefit from international market opportunities in the globalised world [2, 3]. Moreover, IJVs can be a mechanism for transferring knowledge between partners and a way of improving the knowledge and skills of the local partner(s). The success of an

${ }^{1} \mathrm{PhD}$ Student, Oxford Brookes University, UK. organization in today's competitive business environment is strongly related to its ability to utilise knowledge and build their capacity. Managing its knowledge and capacity effectively may help an organization sustain its competitive position in the changing business environment [4]. Knowledge is presented as the most valuable resource and its transfer within and between organisations. It is a key success factor and plays the most significant role for firms. Whether IJV companies benefit from their new international relationship depends greatly on their ability to transfer knowledge.

In the construction industry, globalization together with the information revolution and the improved knowledge-based economy has fundamentally altered the market [5]. Knowledge Transfer (KT) is an important process where an organisation identifies and learns from specific knowledge which exists in another organisation or in its different parts [6]. It has also been recognized as one of the key success factors in the implementation of all types of projects. Furthermore, successful knowledge transfer between partners is not only a key factor to IJVs success but also is an important key objective of growing firms to attract foreign investment through an IJV [7, 8]. Therefore, it is clear from the above discussion of related literature that a better understanding of factors that effecting and influencing on how knowledge in International Construction Joint Venture (ICJV) projects is transferred and adopted is needed. Thus, the main aim of this study is to identify key factors that affect and influence knowledge transfer processes in ICJV Projects.

\section{KNOWLEDGE TRANSFER PROCESS}

The changing business environment has made organisational knowledge a critical factor of business competitive advantage. Knowledge Transfer (KT) plays a critical role in the long term existence of the organisations. Additionally, the KT has been recognised as one of the key success factors of the implementation projects of any type [9]. Lech (2011) defines the knowledge transfer as "a process of exchange of tacit and explicit knowledge between two actors". The purpose of this section is to presents the process of KT and Knowledge creation. Knowledge flows and key factors that influence knowledge transfer processes will then be explained in the conceptual framework section.

As organizations increase their international business activities, they must develop new knowledge and skills involved in international projects. Knowledge flow and its 
transfer are strategically important to organisations for several reasons. According to Nonaka and Takeuchi's (1995) theory of knowledge creation, there are four distinct modes that attribute the success of companies to their effectiveness in the creation of knowledge, the so-called 'SECI Model'. The spiral of knowledge (Exhibits in Figure 1) which represented the dimension of tacit and explicit knowledge and also symbolised the number of people involved in the process. The model is not only explained on knowledge creation but also described process of transferring knowledge.

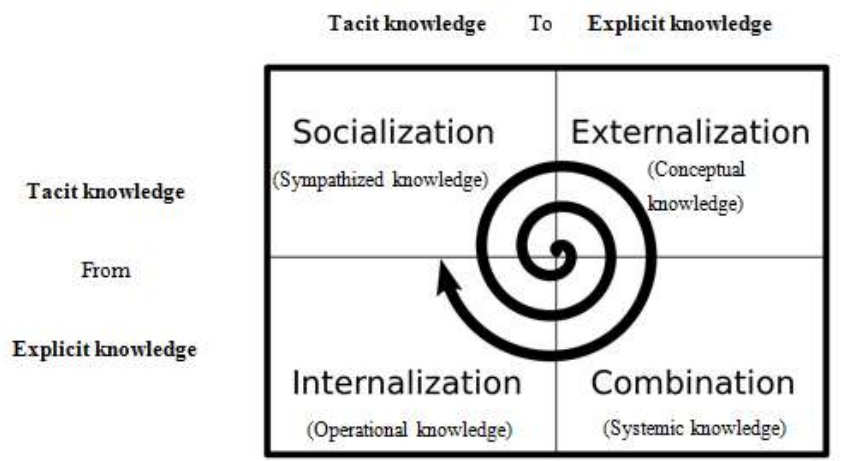

Fig 1: The Knowledge Spiral (Source: Nonaka and Takeuchi (1995, p.62))

\section{FACTORS AFFECTING KNOWLEDGE TRANSFER IN ICJV PROJECTS}

The concept of knowledge transfer process is often treated in literature and is difficult to capture. It is because there is no clear distinction between the transfers of knowledge and the creation of new knowledge. This section examines key enabling and inhibiting factors and knowledge transfer methods and mechanisms which contributed to the development of the conceptual framework of this study. Knowledge flows and knowledge transfer refers to the transfer of either expertise of global relevance. From various literature reviews, there are four main categories of key factors that affect and influence knowledge transfer processes in ICJV projects; ICJVs Performance and ICJVs Success Factors, Knowledge Facilitators, Key enabling and inhibiting factors influencing knowledge transfer in ICJVs and Knowledge transfer methods and mechanisms.

\subsection{ICJVs Performance and ICJVs Success Factors}

The measurement of performance of strategic alliances has been an important research topic in the field of international management [10]. Performance is a complex and multidimensional phenomenon [11]. IJVs performance is defined in term of 1) Project Performance; 2) Performance of the IJV management, 3) Partner Performance, 4) Perceived satisfaction with IJV, 5) Host country conditions and 6) Project-related factors [2, 10, and 11].

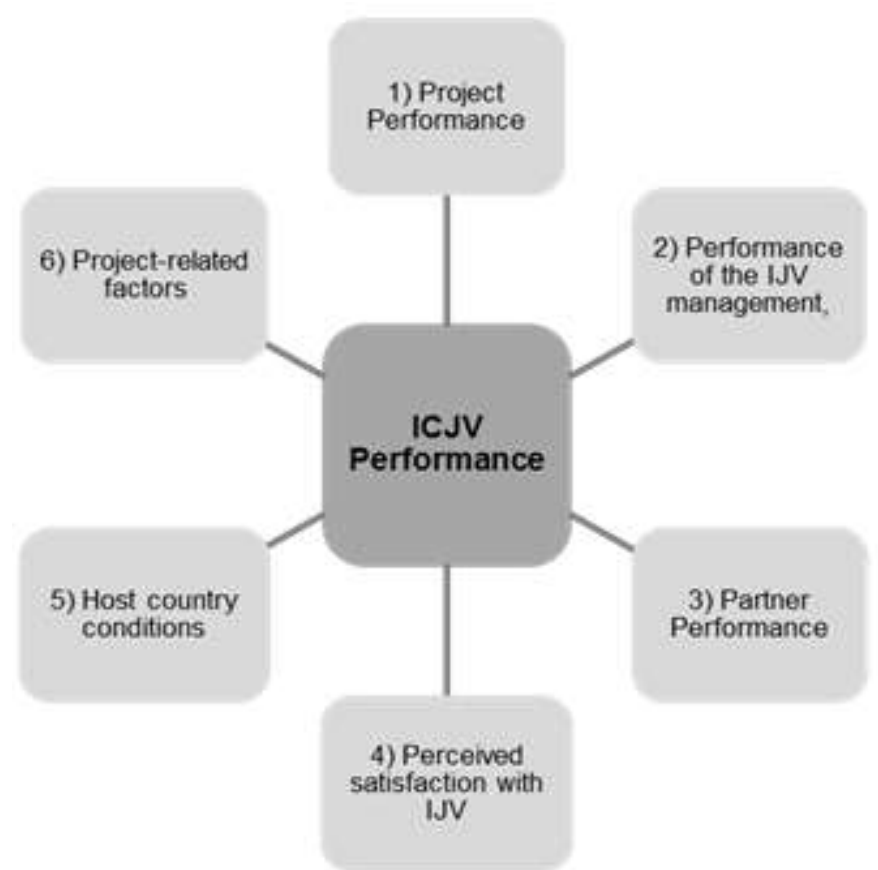

Fig 2: ICJVs Performance (Ozorhon et al., 2007, Ozorhon et al., 2008 and Ozorhon et al., 2011).

- Project performance' is defined as the extent to which the predefined project objectives are realized. IJVs in construction are essentially formed to execute projectbased activities. Part of the operational success of an IJV in the construction industry can be defined in terms of project success.

- 'Performance of the IJV management' is defined by the effectiveness of control over the IJV operation. Control is defined as the influence exercised by the partners over the management of the venture.

- 'Partner performance' measures the extent to which present company objectives are realized as a result of a project undertaken through an IJV. The assessment of IJV performance is to some extent related to the degree to which the objectives of the IJV partners are achieved. 'A partner's satisfaction with the overall performance of the $I J V$ ' is one of the most frequently used subjective measures of IJV performance. The main advantage of these indicators is their ability to provide information regarding the extent to which the IJV has achieved its overall objectives.

'Host country conditions' in this study was defined by political stability, macroeconomic conditions, strength of the legal system and relations with the host government.

'Project-related factors' include relations with other project parties; competence of other project parties; completeness of project definition; availability of resources; technical complexity of the project; completeness of the design; completeness of the contract documents; handling the project requirements in terms of quality, environment, health and safety; penalty sanctions concerning duration; and effectiveness of the project management functions such as planning, coordination, monitoring, and controlling. 
Based on the literature review gathered for this research, it is clear that the success factors of the construction project depends highly on the quality of competent human and entities or organization that are able work as a team in joint venture. More importantly, it is acknowledged that inter-company collaboration entails the requirement of mutual interorganisational commitment and trust and willingness to cooperate in achieving targeted objectives. It seems clear that construction industries of developing countries need to urgently address the problems. Successfully establishing a JV not only offers opportunities for expansion but also bring both parties valuable skills together to carry out projects effectively and efficiently.

\subsection{Factors facilitating knowledge transfer}

Knowledge transfer is a critical aspect of corporate performance in the international arena. Facilitating factors are contextual conditions that weaken of strengthening knowledge flows within the projects. From various literature reviews, there are various factors that facilitate and motivate knowledge transfer in an international construction arena.

'Trust' is definitely a major concern in ICJVs and has an impact on the way partners work together in the ICJVs. Strach and Everett (year of publication) illustrates that 'Trust' among individuals (or organisational unit) is an essential factor in establishing motivations favourable to knowledge transfer. Trust plays an important role mostly in knowledge transfer of tacit knowledge. Trust is also facilitates knowledge transfer since it increases the partners' willingness to assist each other to understand external knowledge. Moreover, Wang and Zhong (2005) states that trust can explain why and how organisational knowledge can be developed in an organisation. As a result, trust determines the degree of knowledge transfer and the efficiency and effectiveness of the process.

Ozorhon et al. (2008) describes that 'Commitment' is the willingness of IJV partners to exert effort on behalf of the IJV. Committed partners are likely interested in creating and maintaining a good relationship with other partners and are interested in to consider long-term gains rather than short-term advantages. Adnan and Moreledge (2003) states that the 'cultural distance' between partners is one contextual factor that stands out in the literature as having an important role in IJV learning. Cultural distance can be defined as the resulting vector of culture-based factors (i.e. languages, values, norms or meanings) that impede the flow of information between partners. In the case of an IJV, cultural distance can produce friction when the parent firms interact with each other at various phases of the IJVs life. 'Prior experience' earned from prior engagement between the partners serves as evidence to justify subsequent risky steps. Moreover, prior relationships indicate a history of repeated interaction, which may lead to relational advantages and stability [2]. Moreover, 'Effective communication' between the IJV partners is important for good inter-partner relations [2]. Communication also allows the partners to understand the goals of the alliance, and the roles and responsibilities of all the actors. Similarly, it also helps with the sharing and dissemination of individual experiences.

3.3 Key enabling and inhibiting factors influencing knowledge transfer in ICJVs and Knowledge transfer methods and mechanisms

To remain competitive companies need to develop strategies to retain this knowledge from older workers and transfer it successfully to other employees in the corporation [12] (Stevens, 2010). Hajidimitriou and Rotsios (2009) posit that factors affecting knowledge transfer can be classified as A) Knowledge related (e.g. type, characteristics and attributes of knowledge) and B) Context related (e.g. organizational and environmental aspects). Table 1 present the categories of key enabling and inhibiting factors in KT. All knowledge transfer methods and mechanisms were extracted from literature review as identified in Table 2 .

TABLE I: FACTORS AFFECTING KNOWLEDGE TRANSFER

\begin{tabular}{|l|l|}
\hline Knowledge Related & Context Related \\
\hline Type of knowledge (Tacit and explicit knowledge) & Motive and Attitude \\
\hline Characteristics of the task and procedure & Time \\
\hline Knowledge distance & The organisational distance \\
\hline The perceived need of knowledge & The size of unit/ organization \\
\hline Knowledge transfer leadership & Individual cognitive style \\
\hline
\end{tabular}


TABLE II: KNOWLEDGE TRANSFER METHODS AND MECHANISMS

\begin{tabular}{|c|c|}
\hline & Knowledge Transfer Methods and mechanisms \\
\hline \multirow[t]{2}{*}{$\begin{array}{l}\text { Technical Knowledge } \\
\text { (Information and } \\
\text { Communication } \\
\text { Technology (ICT)) }\end{array}$} & $\begin{array}{l}\text { Knowledge sharing board, Web-based discussion, Chat rooms/‘Toolbox’ talks } \\
\text { Video conference/ Video-calls } \\
\text { Blogs, Websites, Personal intranets } \\
\text { Communities Of Practices (COPs), E-Learning, Simulation and games } \\
\text { Information system/ Information Technology (Computer-aided system/3d-models) }\end{array}$ \\
\hline & A share best practice database, A categorized knowledge-database, Lesson Learned Database \\
\hline \multirow[t]{7}{*}{$\begin{array}{l}\text { Social Knowledge } \\
\text { (Organizational Structure } \\
\text { and culture) }\end{array}$} & $\begin{array}{l}\text { Experience and Knowledge Sharing } \\
\text { Storytelling/ Sharing best practice/ Information sharing, } \\
\text { Brainstorming }\end{array}$ \\
\hline & $\begin{array}{l}\text { Mentoring and Coaching } \\
\text { Mentoring, Direct teaching and coaching }\end{array}$ \\
\hline & $\begin{array}{l}\text { Meeting or conference and seminar } \\
\text { Group Meeting/ Team meeting, De-briefing Meeting, Ad hoc Meeting, } \\
\text { Lesson-learned Meeting, Minute Meeting, Regular meeting and continuous meeting, Seminar }\end{array}$ \\
\hline & $\begin{array}{l}\text { Training or workshop } \\
\text { On the job training/ Special Training, Formal Training, Apprenticeships } \\
\text { Training with foreign company, Trained in setting out/ site management } \\
\text { Trained in trade skills and site supervision, Trained in proprietary scaffold systems } \\
\text { Induction Training/ Initial training/ Hand-on training, Induction in concentrated courses } \\
\text { Workshop }\end{array}$ \\
\hline & $\begin{array}{l}\text { Visiting } \\
\text { Visiting other projects, Visiting foreign company, Visiting colleagues, } \\
\text { Visiting plants or manufacturers }\end{array}$ \\
\hline & $\begin{array}{l}\text { Interviewing/ Survey } \\
\text { Audio Interviewing, Video interviewing } \\
\text { Survey }\end{array}$ \\
\hline & $\begin{array}{l}\text { Other } \\
\text { Socializing out-of-hours (Lunch or Coffee breaks) } \\
\text { Person-to-person communication (Face-to-face communication) } \\
\text { Telephonic communication, Learning by doing } \\
\text { Memoranda and letters } \\
\text { Project history and Case Writing }\end{array}$ \\
\hline
\end{tabular}

\section{CONCLUSION}

IJVs between multinational organisations in developed and developing countries are considered to be a successful strategy in order to benefit from international market opportunities in the globalised world. Successful knowledge transfer between partners extends to the success and to the performance improvement of the firms. The review of literature presented in this paper underline the need for future research on the conceptual framework that explains the key concepts and the key factors that influence knowledge transfer in ICJV Projects. Base on the research gathered for this paper, it is clear that ICJVs Performance and ICJVs Success Factors, Knowledge Facilitators, Key enabling and inhibiting factors influencing knowledge transfer in ICJVs and Knowledge transfer methods and mechanisms are significant factors that affected and influenced knowledge transfer in ICJV Projects. One possible conclusion could be that developing a conceptual framework based on these key factors should then be identify in order to develop a knowledge transfer framework for joint venture partnerships for the construction companies. Finally, a conceptual framework based on the key concepts and the key enabling and inhibiting factors that influence knowledge transfer will be developed through the future research.

\section{REFERENCES}

[1] MOHAMED, S. (2003). Performance in International Construction Joint Ventures: Modeling Perspective. Journal of Construction Engineering \& Management, 129, 619-626. https://doi.org/10.1061/(ASCE)0733-9364(2003)129:6(619)

[2] OZORHON, B., ARDITI, D., DIKMEN, I. \& BIRGONUL, M. T. (2008). Implications of Culture in the Performance of International Construction Joint Ventures. Journal of Construction Engineering \& Management, 134, 361-370.

https://doi.org/10.1061/(ASCE)0733-9364(2008)134:5(361)

[3] CARRILLO, P. (1996). Technology Transfer on joint venture projects in developing countries. Construction Management and Economics, $14,45-54$.

https://doi.org/10.1080/01446199600000006

[4] KIVRAK, S., ARSLAN, G., DIKMEN, I. \& BIRGONUL, M. T. (2008). Capturing Knowledge in Construction Projects: Knowledge Platform for Contractors. Journal of Management in Engineering, 24, 87-95. https://doi.org/10.1061/(asce)0742-597x(2008)24:2(87)

[5] PIYANUT, W., CHOTCHAI, C. \& WASAN, T. (2009). Strategic Assets Driving Organizational Capabilities of Thai Construction Firms. Journal of Construction Engineering \& Management, 135, 1222-1231. https://doi.org/10.1061/(ASCE)CO.1943-7862.0000091

[6] OSHRI, I. VAN FENEMA, P. KOTLARSKY, J. (2008) Knowledge transfer in globally distributed teams: the role of transactive memory. Information Systems Journal, 18 (6), pp. 593-616. https://doi.org/10.1111/j.1365-2575.2007.00243.x

[7] GALE, A. \& LUO, J. (2004). Factors affecting construction joint ventures in China. International Journal of Project Management, 22, 33-42.

https://doi.org/10.1016/S0263-7863(03)00012-7 
[8] TSANG, E. W. K. (2010). Transferring Knowledge to Acquisition Joint Ventures: An Organizational Unlearning Perspective. Management Learning, 39, 5-20.

https://doi.org/10.1177/1350507607085169

[9] LECH, P. (2011). "Knowledge Transfer Procedures From Consultants to Users in ERP Implementations". The Electronic Journal of Knowledge Management 9(4): $318-327$ available online at www.ejkm.com

[10] OZORHON, B., DIKMEN, I. \& BIRGONUL, M. T. (2007). Using Analytic Network Process to Predict the Performance of International Construction Joint Ventures. Journal of Management in Engineering, 23, 156-163. https://doi.org/10.1061/(asce)0742-597x(2007)23:3(156)

[11] OZORHON, B., ARDITI, D., DIKMEN, I. \& BIRGONUL, M. T. (2011). Toward a Multidimensional Performance Measure for International Joint Ventures in Construction. Journal of Construction Engineering \& Management, 137, 403-411. https://doi.org/10.1061/(ASCE)CO.1943-7862.0000314

[12] STEVEN, R. (2010). "Managing Human Capital: Hoe to Use Knowledge Management to Transfer Knowledge in Today's MultiGeneration Workforce". International Business Research 3(3): 77-82 available online at www.ccsenet.org/ibr https://doi.org/10.5539/ibr.v3n3p77 